\title{
Las percepciones en las Relaciones Internacionales: entre el realismo político y el constructivismo ${ }^{+}$
}

\author{
GONZALO RIVERA* \\ Universidad Nacional de San Agustín de Arequipa \\ gonzaloarnaldo@yahoo.es
}

https://doi.org/10.18800/rcpg.201601.004

\section{RESUMEN}

El presente artículo trata sobre el rol que las percepciones tienen en las relaciones internacionales, contrastando las visiones y aproximaciones que dos escuelas —en principio- opuestas, el realismo y el constructivismo, le dan a esta variable. En su desarrollo se plantea una hipótesis sobre este rol y se la somete a prueba tomando como ejemplo la relación entre el Perú y Chile. Lo que se pretende demostrar es que se puede arribar a una síntesis sobre este tema entre ambas escuelas, aunque son las herramientas del realismo las que nos permiten tener una mejor noción sobre el papel de las percepciones en el comportamiento de los Estados, esto debido a que son los elementos objetivos los que determinan dicho comportamiento. Sin embargo, las percepciones tienen la cualidad de modificar el valor relativo de los elementos objetivos, por lo que es importante conjugar ambas variables en el análisis de las relaciones internacionales.

Palabras clave: Constructivismo, Chile, percepciones, Perú, realismo, relaciones internacionales.

\section{Perceptions in International Relations: Between Political Realism and Constructivism.}

\begin{abstract}
The purpose of this article is to analyze the role of perceptions in international relations, confronting the approach given to this subject by two theoretical schools: realism and constructivism. To do this analysis, this article proposes a hypothesis and tests it using the relations between Chile and Peru. The aim is to demonstrate that is possible to synthesize the role given to ideas and images by these two schools. However, it would be the paradigms of realism that allows us to have a better understanding of perceptions in the behavior of States, because their decisions are based primarily upon objective considerations. Nevertheless, perceptions would have the potential to modify the relative value of those material determinants, and that is the main reason to combine both of them in the analysis of international politics and States choices.
\end{abstract}

Key words: Constructivism, Chile, perceptions, Peru, realism, international relations.

\footnotetext{
* Máster de investigación en Estudios Políticos en la Universidad de París II, Panthéon - Assas; y máster en Ciencia Política - Relaciones Internacionales en la Universidad Jean Moulin, Lyon 3.

+ Recibido el 24 de mayo de 2016; aceptado el 22 de octubre de 2016.
} 

¿Las percepciones, imágenes o ideas tienen una verdadera influencia en las decisiones que los Estados toman en sus asuntos exteriores? Esta es una pregunta que varios académicos se han planteado desde hace varios años atrás. En efecto, Kenneth Boulding en 1959 (Roche 2008: 137) ya teorizaba acerca del impacto que las imágenes pueden tener en las relaciones internacionales, y en 1957 los esposos Sprout hablaban de la importancia de las percepciones y las ideas en la toma de decisiones por parte de los responsables del manejo de la política exterior de un Estado.

No obstante que esta inquietud sobre el mundo de las ideas y las percepciones no es nueva, aún se mantiene la discusión en esta temática. Es en este marco que el presente artículo pretende aportar al debate teórico, proponiendo una hipótesis sobre el rol que las percepciones tendrían en las relaciones internacionales y sometiéndola a prueba, tomando como ejemplo la relación entre el Perú y Chile.

Para tal propósito, haremos nuestro análisis usando las aproximaciones de dos escuelas: la corriente racionalista del realismo y la escuela epistémica, del constructivismo. Si bien en ambas se habla sobre las percepciones y las capacidades materiales, cada una privilegia una sobre la otra: el constructivismo a aquellas y el realismo a estas últimas. Es en ese sentido que aún se mantiene el debate sobre el peso exacto que cabe a las ideas e imágenes en el análisis político. En efecto, del lado de buena parte de los autores realistas las percepciones son variables dadas y por tanto no tienen mayor o ninguna influencia en el comportamiento de los Estados, y por el contrario para ellos son los elementos materiales los que determinan el comportamiento de un actor internacional. Esto fue identificado en una investigación que llevaron adelante Legro y Moravcsik (1999) como el tercer elemento central que diferencia a la escuela realista —en todas sus variantes: realismo clásico, neorrealismo, realismo liberal, realismo defensivo, realismo ofensivo o realismo hegemónico- de las demás escuelas dentro de la teoría de las relaciones internacionales. En el otro extremo tenemos a los autores constructivistas que, por el contrario, sostienen la primacía de las ideas sobre las demás variables, puesto que es justamente sobre la base de esas imágenes e ideas que se construyen (de ahí el nombre) las relaciones dentro de la sociedad internacional. Sobre esto último resulta ilustrativo el planteamiento de uno de los mayores exponentes de la escuela epistémica Alexander Wendt, quien afirma que «la significación del poder y el fondo de los intereses está en gran parte en función de las ideas» (1999: 96). 
Es con la lógica hegeliana de tesis, antítesis y síntesis — del racionalismo frente al constructivismo - que se encuadra la hipótesis que se plantea en este artículo. Es completamente lógico pensar que estos dos elementos, lo objetivo y lo subjetivo, influyen en las elecciones sobre los asuntos de política exterior de los Estados. En efecto, como ya indicamos, incluso un autor del realismo clásico como Raymond Aron reconoció que existe un lugar para las ideas y los sentimientos en la explicación del comportamiento de un actor internacional: «la conducta externa de los Estados no es guiada sólo por la relación de fuerzas: ideas y sentimientos influyen en las decisiones de los actores» (Aron 1984: 108).

Así, tomando la idea de que sí es posible lograr una síntesis entre las diversas escuelas de las relaciones internacionales - en este caso específico respecto del peso que las percepciones tienen en las decisiones de los Estados-, tal como lo sugiere el esquema de análisis propuesto por Brecher (1999), ${ }^{1}$ en este artículo ensayaremos plantear una postura intermedia que se valga del racionalismo y del constructivismo. Partiremos de la premisa básica de que los elementos materiales son esenciales para poder comprender y predecir las decisiones de política exterior de los Estados. Pero estos elementos no son los únicos a tener en cuenta al analizar el comportamiento de un actor en la esfera internacional, incluso si estos, como teoriza el realismo, puede que sean los más importantes.

Consideraremos que las percepciones también son importantes para poder comprender de manera adecuada las motivaciones que impulsan a un Estado a actuar de una determinada manera. Al respecto, seguiremos la noción propuesta por Robert Jervis de que «es imposible explicar las principales decisiones [de un Estado] sin tomar en cuenta las ideas, las creencias que sobre el mundo tienen los responsables de la toma de decisiones al interior de los Estados» (1976: 28). En esa línea, la noción básica del modelo teórico que planteamos es que los elementos objetivos así como las percepciones (en donde podemos incluir las ideas y los sentimientos) tienen una influencia,

\footnotetext{
Este esquema busca poder crear síntesis entre planteamientos teóricos en debate, y no considerarlos, a priori, como mutuamente excluyentes en su totalidad: «Se requiere un esfuerzo sostenido para desplazarse del síndrome de la tesis y la antítesis a la síntesis en cada faceta del campo [de las relaciones internacionales]. [...] Sin la integración del conocimiento, que sea revisada cada cierto tiempo a la luz de nuevos aportes teóricos, métodos mejorados y nueva evidencia, los estudios internacionales están destinados a permanecer como una colección aislada de piezas de explicación de la realidad y el comportamiento. La síntesis entre la mayoría de las dicotomías presentes entre las distintas escuelas de las relaciones internacionales es posible, de hecho esto ha sido logrado en el programa de investigación 'International Crisis Behavior', que se enfoca en el estudio e investigación de conflictos, crisis y guerras internacionales» (Brecher 1999: 252. El texto original es en inglés, esta es una traducción libre del autor).
} 
una causalidad, en las elecciones que se toman en política exterior. ${ }^{2}$ Para continuar dando forma a nuestra propuesta, podemos añadir la interpretación ofrecida por Bull, Bøås y McNeill, según la cual:

las relaciones internacionales se componen tanto de elementos materiales como de ideas. Estas últimas le dan una dirección y una causa al poder material, definiendo las prioridades; mientras que las capacidades materiales pueden hacer que los actores cambien sus ideas y sus prioridades [... Las ideas son formadas para corresponder a los intereses y a las estrategias, pero lo contrario también es cierto (2004: 489).

La hipótesis central que planteamos en este artículo es que en un ambiente anárquico de competencia de los Estados los elementos objetivos, sus capacidades materiales, constituyen la base de sus relaciones exteriores. Sin embargo, al ser el Estado una construcción social, dirigida por personas, en la que pese a que sus decisiones son guiadas en la mayoría de casos por determinantes fijas (el interés nacional), estas personas tienen su propia percepción del mundo, la que puede dar una cierta dirección a los elementos materiales en el comportamiento de dicho Estado, modificando el valor relativo de esos elementos objetivos en función de su visión particular del mundo. Así, en las elecciones de política exterior los elementos objetivos serían la base fundamental para explicar el comportamiento de un determinado actor estatal, pero las percepciones tendrían el efecto de modificar el valor relativo de esas capacidades materiales (las propias y las de los demás actores), aumentando o reduciendo tal valor. De manera análoga a una ecuación exponencial en la que existe un número en la base (que serían los elementos materiales con un valor estable y conocido, pasible de ser medido), pero este número es modificado por el exponente que representa las percepciones (cuyo valor es variable y de difícil cuantificación, aunque en este caso al menos sí es posible saber si la percepción de un determinado actor o de una determinada situación es positiva o negativa).

Para poner a prueba nuestro modelo teórico analizaremos la relación bilateral del Perú con Chile en un esquema de tres partes. Primero, comenzaremos por tratar de demostrar la preeminencia de lo objetivo sobre lo subjetivo (tal como plantea el realismo), poniendo a prueba el planteamiento teórico de Alexander Wendt a través de episodios de la historia común de ambos países. Luego, en una segunda parte, y a fin de demostrar que las percepciones mutuas tienen un verdadero impacto en las elecciones de política exterior, haremos

2 Cf. con la siguiente afirmación de Goldstein y Keohanne: «[...] we do not argue that ideas rather than interest (as interpreted by human beings) move the world. Instead, we suggest that ideas as well as interest have casual weight in explanations of human action» (1993: 3-4). 
un breve análisis de la relación bilateral contemporánea. Finalmente, en la tercera parte introduciremos la idea del interés nacional, lo que nos ayudará a comprender de una mejor manera los principales elementos en juego de la relación bilateral y ver de qué manera estos están unidos a los elementos materiales y que son justamente las percepciones un factor que modificaría el valor relativo de aquellos.

\section{LA HISTORIA CONFLICTIVA DE UNA VECINDAD}

Como ya hemos indicado, la principal discrepancia entre los enfoques realistas y constructivistas es la concepción acerca de las fuerzas que le dan forma al mundo. Para aquellos son los elementos materiales los que están en el centro de su análisis como el principal condicionante en la conducta de los Estados. En cambio para los constructivistas el mundo es el producto de un proceso de construcción social marcado por las ideas de los actores.

Justamente de este último enfoque tomaremos el planteamiento de Alexander Wendt para analizar la relación bilateral que usamos de ejemplo. Según la propuesta del autor constructivista, «si el 'self-help' no es una característica constitutiva de la anarquía, éste debe surgir de manera espontánea producto de un proceso [...], de la interacción», en lo que Wendt considera el segundo principio del constructivismo (1992: 403). Al respecto, dicho autor emplea el siguiente ejemplo:

Considérense dos actores [...] que se encuentran el uno con el otro por primera vez. Cada uno quiere sobrevivir y tiene determinadas capacidades materiales [...] y no existe entre ellos historia de seguridad o inseguridad. ¿Qué deberían hacer? Los realistas probablemente sostendrían que cada actor actuaría sobre la base de las presunciones del peor escenario posible respecto de las intenciones del otro actor, justificando que tal actitud sería la prudente en vista de la posibilidad de morir en caso de tomar la decisión equivocada. Tal posibilidad siempre existe [...] sin embargo, la sociedad sería imposible si las personas tomasen sus decisiones solamente sobre la base de las posibilidades del peor escenario. En cambio, muchas de las decisiones se adoptan sobre la base de probabilidades y éstas son producto de la interacción (1992: 404). ${ }^{3}$

Entonces, pondremos a prueba este enunciado para validar o negar la hipótesis sugerida por Wendt. Para tal propósito tomemos la relación bilateral entre el Perú y Chile en un contexto histórico. Ambos países fueron colonias de España desde el siglo XVI y pese a las reparticiones administrativas durante ese periodo toda la América del Sur hispanohablante estaba bajo la unidad de la

3 El texto original está en inglés, por lo que esta es una traducción propia del autor. 
corona española, por tanto los intereses superiores de estos dos territorios eran los mismos. Esto no quiere decir que no hubiesen intereses locales que pudiesen estar en disputa, pero la primacía era la de los intereses de la corona, lo que hacía que se tuviese un interés común a ambos. Así, vemos que la condición inicial que supone Wendt (la no existencia de una historia de inseguridad) está presente. Pero, contrariamente a la afirmación del autor constructivista, podemos ver que al momento de su independencia (1817-1824) fueron los elementos materiales los que condicionaron el origen de la relación bilateral. Es decir, por más que exista una influencia mutua entre lo material y lo inmaterial, fueron los elementos materiales los que se impusieron, que es justamente la concepción realista que cita Wendt. La mejor prueba de esto es que a los pocos años de haberse logrado la independencia del Perú, que contó con el apoyo de la naciente República de Chile, y cuando se forma la Confederación PeruanoBoliviana (1836-1839), Chile temía que las capacidades materiales de estos dos Estados confederados superasen a las suyas, lo que amenazaba su existencia, tal como lo expresó Diego Portales en su celebérrima carta a Blanco Encalada:

[...] La posición de Chile frente a la Confederación Perú Boliviana es insostenible. No puede ser tolerada ni por el pueblo ni por el Gobierno porque ello equivale a su suicidio. No podemos mirar sin inquietud y la mayor alarma, la existencia de dos pueblos, y que, a la larga, por la comunidad de origen, lengua, hábitos, religión, ideas, costumbres, formarán, como es natural, un solo núcleo. Unidos estos dos Estados, aun cuando no más sea que momentáneamente, serán siempre más que Chile en todo orden de cuestiones y circunstancias [...] La Confederación debe desaparecer para siempre jamás del escenario de América por su extensión geográfica; por su mayor población blanca; por las riquezas conjuntas del Perú y Bolivia, apenas explotadas ahora; por el dominio que la nueva organización trataría de ejercer en el Pacífico arrebatándonoslo; por el mayor número también de gente ilustrada de la raza blanca, muy vinculadas a las familias de influjo de España que se encuentran en Lima; por la mayor inteligencia de sus hombres públicos, si bien de menos carácter que los chilenos; por todas estas razones, la Confederación ahogaría a Chile antes de muy poco [...] Las fuerzas navales deben operar antes que las militares, dando golpes decisivos. Debemos dominar para siempre en el Pacífico: ésta debe ser su máxima ahora, y ojalá fuera la de Chile para siempre [...] (Villalobos 1990: 173-175).

Sobre este asunto cabe preguntarse por qué una década antes Chile apoyó al Perú a concretar su independencia, mientras que en ese momento la visión era la de un enemigo al cual temer y por tanto había que lanzar un ataque preventivo. La respuesta está en que más que relaciones de cooperación derivadas de una primigenia interacción entre los dos Estados nacientes, el apoyo dado por Chile al Perú respondía a garantizar la propia seguridad de Chile (acción congruente con el postulado del self-help). Efectivamente, los análisis históricos coinciden 
en sostener el hecho de que ninguna de las nuevas naciones de la América del Sur podía concretar su independencia si es que el Perú hubiese continuado bajo el control de los españoles, dado que el Virreinato del Perú y en especial su capital, Lima, era el principal centro del poder de España en Sudamérica y por tanto tenía el potencial de retomar las conquistas de los territorios sublevados; de ahí los esfuerzos venidos desde el sur y el norte del subcontinente para consolidar la independencia en territorio peruano.

Posterior a la guerra contra la Confederación se sucederían episodios de acercamiento (como la acción conjunta contra la flota española en 1866 o la defensa común de la tesis de la soberanía marítima de las 200 millas de fines de los años 1940) y distanciamiento (la disputa por la soberanía de Tacna y Arica de comienzos del siglo XX o las tensiones de los ańos 1970), todos ellos marcados por la idea de la propia seguridad y de garantizar la supervivencia y supremacía de uno de los dos Estados en las costas del Pacífico sur, y cuyo mayor hito sería la Guerra del Pacífico, hecho que está presente en el imaginario de ambos países incluso hasta nuestros días. Al respecto, y para ver un nuevo ejemplo del postulado realista del self-help en la relación bilateral, tomemos la siguiente concepción:

En un primer momento, este [sentimiento de amenaza] emerge como respuesta y consecuencia de la formación de la Confederación Perú-Boliviana en 1836. La guerra defensiva que el Estado chileno entabla en contra de esta amenaza percibida como determinante y decisiva, utilizando el concepto avanzado por Diego Portales, para la supervivencia nacional en los primeros años de nuestra vida republicana.

Subsecuentemente, la Guerra del Pacífico también se daría como objetivo garantizar la supervivencia del Estado-nación chileno.

Transitamos, de esta manera, desde la problemática de un politicidio absoluto, ilustrada por la postura subregional del Mariscal Santa Cruz, hacia la pérdida, lenta pero progresiva, de la capacidad de influencia chilena en el Pacífico, de allí, al aumento en las capacidades bélicas del vecino peruano y boliviano como consecuencia de los ingresos que los yacimientos de guano, primero, y de salitre luego. La Guerra del Pacífico, siendo un conflicto bélico defensivo en términos políticos, pero ofensivo en términos doctrinarios, permitirá a Chile garantizar una relativa pero activa influencia en las costas de su mar adyacente (Leyton 2006: 7-8).

La historia común nos demuestra cómo, después de este momento inicial de la relación que fue condicionada por los elementos materiales, ambos actores comenzaron un proceso de formación de percepciones mutuas que siguió el 
mismo esquema del «dilema de seguridad» de Robert Jervis. ${ }^{4}$ En otras palabras, de acuerdo a la hipótesis planteada en el presente artículo, en el primer contacto que tuvieron los Estados como tales, fueron los elementos materiales los que marcaron ese momento inicial y la interacción posterior, lo que produjo un sentimiento de competencia. Este sentimiento modificó a la vez el valor relativo de los elementos materiales aumentando así la percepción de competencia y rivalidad, lo que terminó por crear un proceso en espiral que forjó una imagen de desconfianza y rivalidad mutua, la cual se aprecia en diversos pasajes de la historia como la Guerra del Pacífico o las tensiones en los años 1970 durante los gobiernos militares de Velasco y Pinochet; así como en los escritos de uno y otro país.

Contrariamente a lo que plantea Wendt, el contexto subjetivo de 1820-1830 era favorable para la construcción de relaciones cordiales y de cooperación entre el Perú y Chile. Empero, la mayor capacidad material de un Estado (el Perú), que podía verse ampliada por la unión con otro Estado (Bolivia), hizo que los estadistas chilenos, en especial Diego Portales, considerasen justamente la hipótesis del peor escenario posible, en la que se visualizaba una seria amenaza a la seguridad e intereses chilenos, por lo que era necesario emprender una guerra en contra de la Confederación (un ataque preventivo), y de manera análoga se tendría que emprender una segunda guerra, la del Pacífico, hecho que no solo cambiaría el balance de los factores materiales entre los actores sino que marcaría además, de forma decisiva y duradera, las percepciones mutuas.

En esta relación existirían cuatro factores, tanto objetivos como subjetivos, que han alimentado a lo largo de toda la historia común la percepción de amenaza y rivalidad (Leyton 2006: 1-2):

(1) La rivalidad por la posesión de los espacios geográficos, que implica además el control de recursos naturales de alto valor estratégico;

(2) los conflictos armados a gran escala con la ocupación militar y política de un territorio, en especial de espacios con un alto valor simbólico para la conciencia y el orgullo nacional, como fue el caso de Lima;

(3) la amputación territorial del país vencido; y

(4) la instrumentalización política de los conflictos para construir una alta cohesión nacional, por la oposición al enemigo.

\footnotetext{
4 Para profundizar en este asunto puede consultarse el artículo «Cooperation under the security dilemma» de Robert Jervis (1978), o el de Barry Posen (1993): «The security dilemma an ethnic conflict».
} 
Lo anterior, que derivó en los conflictos armados y a la vez devino de ellos, creó en el imaginario popular una visión de «adversarios históricos» con las siguientes imágenes y visiones (Milet 2004: 228):

(1) De vencedor y de vencido;

(2) de invasor y de invadido; $y$

(3) de Estado depredador y de Estado revanchista.

Producto de esa historia de rivalidad y confrontación, la idea de desconfianza se instaló de una manera muy fuerte en la percepción de buena parte de sus pobladores: para muchos en el Perú las máximas de Diego Portales marcaron a las élites gobernantes, políticas, militares y parte de la población chilena durante todo el siglo XIX y XX, lo que creó en el imaginario popular una visión de un Estado depredador que busca aumentar su lebensraum a costa del espacio físico y los recursos del Perú. En un contexto de paz, esta invasión se daría con las inversiones. Por ejemplo, una encuesta hecha en Lima en 2009 reveló que el $54 \%$ de la población de Lima consideraba como poco o nada beneficioso para el Perú las inversiones de capitales chilenos. ${ }^{5}$ De forma similar, una encuesta en 2009 señalaba que solo el 2\% de la población limeña veía a Chile como el mejor amigo del Perú. ${ }^{6}$ Encuestas de los años 1996 y 1957 revelan que esas percepciones eran similares en aquellos años; y por el lado chileno, los indicadores son similares ${ }^{7}$ con la visión del «revanchismo peruano».

Entonces, vemos así que la relación bilateral entre estos dos Estados se puede explicar mejor con los parámetros del realismo que con los del constructivismo. Efectivamente, la propia hipótesis de Wendt nos confirma, en el caso del Perú y Chile, la validez de la afirmación de Morgenthau (1993: 3): «nuestro mundo es un mundo de intereses opuestos y conflictivos, [y que se rige por...] el equilibrio siempre temporal de intereses y por la conciliación siempre precaria de los conflictos».

\section{LOS SOCIOS Y RIVALES}

En el punto precedente sostuvimos que los elementos objetivos (capacidades ofensivas, acceso a recursos naturales y control de los espacios geográficos) condicionaron desde un principio la relación bilateral, y que la competencia,

\footnotetext{
«La inversión de Chile en Perú bate récord en el primer semestre» (Gestión 2009a).

«Brasil es el mejor amigo del Perú» (Gestión 2009b).

7 Ver «Las Américas y el Mundo: Política exterior y opinión pública en Colombia, Chile, México y Perú 2008» (Centro de Investigación y Docencia Económicas 2009) e «Informe de prensa, encuesta nacional» (Centro de Estudios y de la Realidad Contemporánea 2006).
} 
la rivalidad y la guerra sembraron una percepción de conflicto y desconfianza fuertemente arraigada. Sin embargo, en los últimos ańos otros elementos objetivos (la vecindad, la similitud de culturas, regímenes económicos y políticos similares, la complementación económica, etcétera) han creado una situación particular en la que se cohabita, se coopera, y se establecen mecanismos de cooperación e integración para crear una alianza, a pesar de que en el imaginario nacional de cada país subsiste aún la percepción de competencia. Desde hace poco más de veinte años ambos países han ido aumentando su interdependencia, especialmente económica así como un acercamiento ideológico que se ve claramente plasmado en la Alianza del Pacífico, lo que los convierte en verdaderos socios. Además, estos Estados mantienen no solo relaciones internacionales sino también relaciones transnacionales —entre autoridades distintas del ejecutivo, empresarios, y ciudadanos - cada vez más importantes.

En la actualidad es poco probable pensar que se dé un escenario de guerra entre ambos Estados por diversas consideraciones. El nivel de interdependencia es tan alto que en caso de un conflicto los intereses de las colonias de migrantes, de las ciudades vecinas y de los empresarios, fuertemente ligados al poder político, se verían seriamente afectados. Además ambos Estados han privilegiado los mecanismos de solución pacífica de controversias (como el Tratado de Bogotá de 1948 o la Carta de las Naciones Unidas). De otro lado, los estudios especializados en conflictos como el Conflict Data Program de la Universidad de Uppsala o el Global Peace Index muestran que la región es una zona relativamente pacífica y cuyas mayores amenazas corresponden más bien a amenazas infra-Estados, derivadas de ilícitos transnacionales.

Evidentemente, una alta interdependencia y la aceptación de los mecanismos del derecho internacional no significan la exclusión del uso de la fuerza, pero sí hace que su utilización sea más costosa y que por tanto los actores prefieran no usarla. Ahora bien, en países en desarrollo en un contexto de interdependencia y de relativa paz regional podría esperarse una reducción del presupuesto en defensa: en una situación de recursos limitados se privilegian las necesidades más urgentes.

Sin embargo, como vemos en los cuadros inferiores, los gastos militares en alrededor de un siglo han mostrado una tendencia hacia el alza con un cierto comportamiento de acción y reacción, observándose un claro punto de inflexión en los años 1970, década en la que en Chile se visualizaba la existencia de una amenaza por el «revanchismo peruano». Esto se debería a que aún subsiste la sensación de rivalidad creada por los elementos materiales de un comienzo, 
potenciada por la desconfianza forjada en el proceso de interacción. Así, los gastos militares no siguen las tendencias de la integración económica. La visión del «vecino rival» permanece aún en las percepciones de las poblaciones de ambos países.

\section{Gráfico 1. Perú-Chile, gasto en defensa 1925-2007 (miles de US\$)}

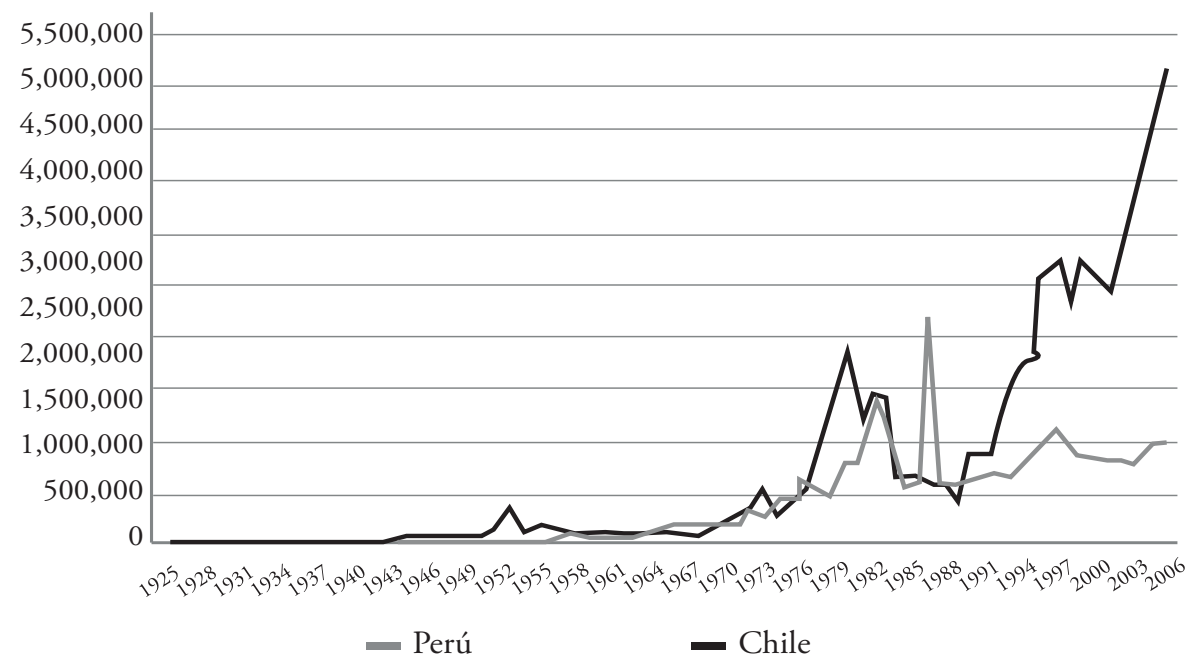

Fuente: The Correlates of War Project, National Material Capabilities data set (v 4.0); (Singer et al. 1972: 19-48; y Singer 1987: 115-132).

Elaboración propia.

La explicación hipotética que se propone es que existe una relación entre la acumulación de capacidades militares con las percepciones mutuas, lo que nos mostraría que las percepciones tienen un impacto real en las elecciones de política de un Estado.

En ese contexto, la idea de un posible conflicto llevaría a suponer, en el peor escenario posible, que el uso de la fuerza es una posibilidad dado que en situaciones extremas toda potencia tiene que defender sus intereses nacionales con el uso de la fuerza o la amenaza de utilizarla si es necesario. Es evidente que la posibilidad del uso de la fuerza es ahora menor dado que el sistema internacional ha cambiado, y hoy en día las limitantes para su empleo son mayores que en el pasado, pero esta no está prohibida y al fin y al cabo es la prerrogativa final de los Estados usarla, porque frente a una amenaza de desaparición o de afectación de su soberanía el Estado hará todos sus esfuerzos para sobrevivir, lo que es reconocido por el derecho internacional (véase el artículo 51 de la Carta de 
las Naciones Unidas o la doctrina del ataque preventivo de los EE.UU.). De ese modo, en un escenario de competencia y conflicto un Estado querrá tener una capacidad militar suficiente para resguardar su seguridad frente a todas las amenazas que deba enfrentar, reales o potenciales, estatales o no estatales, y mejor si puede disuadir a sus rivales de no atacarlo ya que esta sería la alternativa menos costosa (Maersheimer 2005).

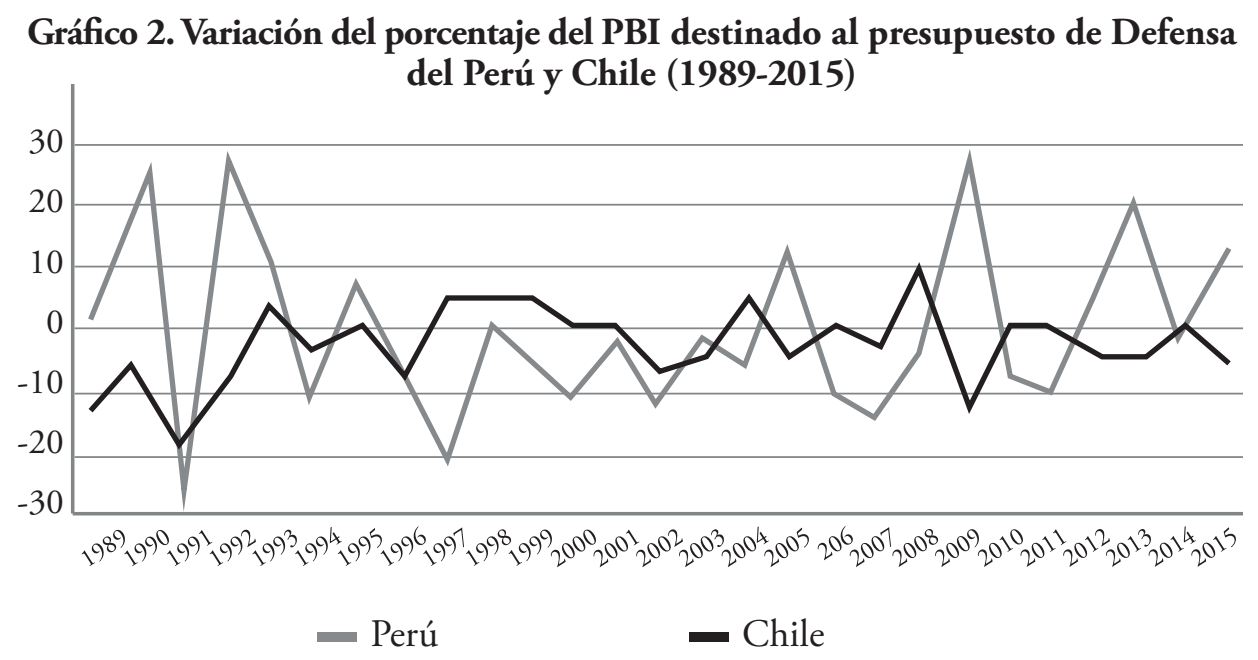

Fuente: The Correlates of War Project, National Material Capabilities data set (v 4.0); (Singer et al. 1972: 19-48; y Singer 1987: 115-132).

Elaboración propia.

De otro lado, pese a la interdependencia económica que existe en la actualidad entre ambos Estados, se observan elementos de competencia en lo estratégico y económico. Como vimos en el apartado anterior, la competencia y rivalidad entre ambos Estados apareció casi al mismo tiempo que su independencia, y diversos historiadores están de acuerdo en que el leitmotiv de esa rivalidad era de naturaleza económica: la explotación de materias primas (guano y salitre) así como el control de las vías marítimas y de comercio (Aljovín y Cavieres 2005, Leyton 2006). Primero el guano, luego el salitre, estas dos materias primas fueron productos claves de la economía del Pacífico sur de la época y una de las principales causas de la Guerra del Pacífico. En la actualidad tenemos al cobre como la materia prima de la región, en cuyo comercio ambos países compiten (Chile como el primer productor mundial con el 34\% de la producción total, y el Perú como el segundo productor con el $8 \%$ de la producción). Vemos aquí 
una constante histórica de las riquezas naturales de la región, que llevaron en el pasado a ambos Estados hacia el conflicto.

El otro elemento, más importante, es la competencia por las vías de comunicación, la rivalidad entre los puertos peruanos y los chilenos por la primacía en el Pacífico sur, en especial entre los puertos del Callao y el de Valparaíso, pero también entre los demás puertos secundarios. Aquellos dos grandes puertos con miras a convertirse en el hub regional en esta zona del Pacífico.

\section{EL INTERÉS NACIONAL}

En el paradigma del realismo el Estado actúa dirigido por intereses, por tanto este es un elemento clave para esta escuela de las relaciones internacionales, tal como lo afirma Morgenthau, quien sostiene que «nuestro mundo es un mundo de intereses opuestos y en conflicto [en donde] los principios morales no pueden siempre realizarse plenamente. Pero al menos podemos acercarnos a ello gracias al equilibrio siempre temporal de intereses y a la condición siempre precaria de los conflictos» (1993: 3-4). Para el realismo el interés es la acción que guía la política exterior de un Estado. Entonces, en un mundo en competencia en el que los Estados buscan satisfacer sus intereses y que algunos de ellos pueden ser antagonistas con los intereses de otro(s) Estado(s), estos intereses se convierten por tanto en una fuente potencial de conflicto. Sin embargo, la búsqueda de satisfacer los intereses nacionales no significa una condena a la competencia perpetua. La conciliación de intereses puede llevarnos a periodos de paz y cooperación entre los actores. Así, Thomas Robinson (1969), a partir de la teoría de Morgenthau, nos ofrece una clasificación de los intereses nacionales según su grado de comunidad: intereses en conflicto, complementarios y comunes (enfoque triangular). Los primeros llevan a la rivalidad y al conflicto, mientras que los otros dos pueden llevar por el contrario a la cooperación.

Entonces, vemos que el concepto de interés nacional es una herramienta muy potente para poder comprender de manera adecuada el comportamiento de los actores en el campo de las relaciones internacionales, y en nuestro caso de estudio no sería la excepción, al menos la historia así lo ha demostrado. En ese sentido, serán los elementos materiales en juego los que nos ayudarán a comprender la relación bilateral. Con esta aseveración, veamos ahora algunos de esos elementos materiales ligados entre sí: el mar, la competencia de los puertos y la proyección al Asia-Pacífico. Al menos los dos primeros elementos no son nuevos y por el contrario han estado siempre en el contexto histórico de su vida independiente. 
Para ambos países el mar es un elemento central de su visión de país. El Perú se considera asimismo como un Estado marítimo, andino y amazónico (García Bedoya 1981. Ver también el Ministerio de Defensa del Perú 2005: 49). Por su parte, la geografía hace de Chile un país netamente marítimo: de acuerdo a su concepción los accidentes geográficos de su territorio le dan un carácter insular (Ministerio de Defensa de Chile 2002: 29). Solo el 27\% de su territorio es apto para ser habitado, lo que hace que Chile dé una importancia radical al mar:

Los espacios marítimos [...] son indispensables para el desarrollo y la vida de nuestro país [...] lo estrecho del territorio nacional y la poca flexibilidad de las vías de comunicación terrestres y aéreas, obligan que la mayor parte de los transportes operativos, de las fuerzas militares y de sus apoyos administrativos y logísticos se realicen utilizando las vías de comunicación marítimas nacionales (Ministerio de Defensa de Chile 2010: 71).

Esta fuerte ligazón de Chile con el mar fue establecida desde su aparición a la vida independiente, cuando O'Higgins sostenía que la independencia no servía de nada si es que Chile no llegaba a dominar el mar (Armada de Chile 2009: 12). Igualmente debe recordarse la máxima de Portales: «Por el dominio que la nueva organización [la Confederación Peruano-Boliviana] trataría de ejercer en el Pacífico arrebatándonoslo [...] Debemos dominar para siempre en el Pacífico: ésta debe ser su máxima ahora, y ojalá fuera la de Chile para siempre». Más de un siglo después, en 1968, Pinochet publicó su obra Geopolítica, en la que afirmaba que «el mar es un gran [elemento] auxiliar de la grandeza y el poder de los Estados, con una influencia geopolítica que es necesaria considerar para estudiar su futuro en el conjunto de las naciones» (1977: 89). Esta noción del carácter marítimo de Chile ha dado pie a la creación del concepto del «mar presencial chileno». ${ }^{8}$ En ese marco se podría entender que el litigio que planteó el Perú ante la Corte Internacional de Justicia por los límites marítimos de ambos países se haya visto en Chile como un momento a partir del cual «las relaciones bilaterales con Perú sufrieron un lógico retroceso. Para Chile, esta presentación no fue un gesto amistoso sino que una construcción artificial» (Ministerio de Relaciones Exteriores de Chile 2010: 15). La posición peruana en ese litigio podría haberse entendido no solo como un probable cambio a su

\footnotetext{
8 «Parte de Alta Mar entre el límite de la Zona Económica Exclusiva de Chile y el meridiano que, pasando por el borde occidental de la Plataforma Continental de Isla de Pascua, se prolonga desde el paralelo del hito No 1 de la línea fronteriza internacional que separa Chile de Perú, hasta el Polo Sur; donde Chile compromete su presencia para proteger la vida humana y preservar el medio ambiente. [...En este espacio, Chile] ha asumido una serie de responsabilidades internacionales relacionadas con la protección de la vida humana en el mar, el control del tráfico marítimo y la conservación del medio ambiente. En este espacio de mar, Chile busca proyectar los intereses marítimos propios y de toda la comunidad internacional, vigilando el medio ambiente y conservando los recursos marinos, con irrestricto apego al derecho internacional. Considera el ejercicio de actividades de investigación, prospección y productivas, individualmente o en conjunto con otros estados, con miras al desarrollo nacional» (Armada de Chile 2009: 34-35).
} 
territorio, sino también como una amenaza a la concepción chilena del «mar presencial», lo que tendría una mayor afectación de los espacios geográficos. Sobre este asunto, podríamos rescatar el siguiente postulado de un autor de Geopolítica: «a diferencia de los territorios en los que el equilibrio de fuerzas puede establecerse, el mar empuja hacia la hegemonía; el mar no se comparte. La historia marítima es una sucesión de monopolios» (Chaupadre 2003: 560).

\section{Diagrama 1. Espacios marítimos de Chile según su concepción de Defensa}

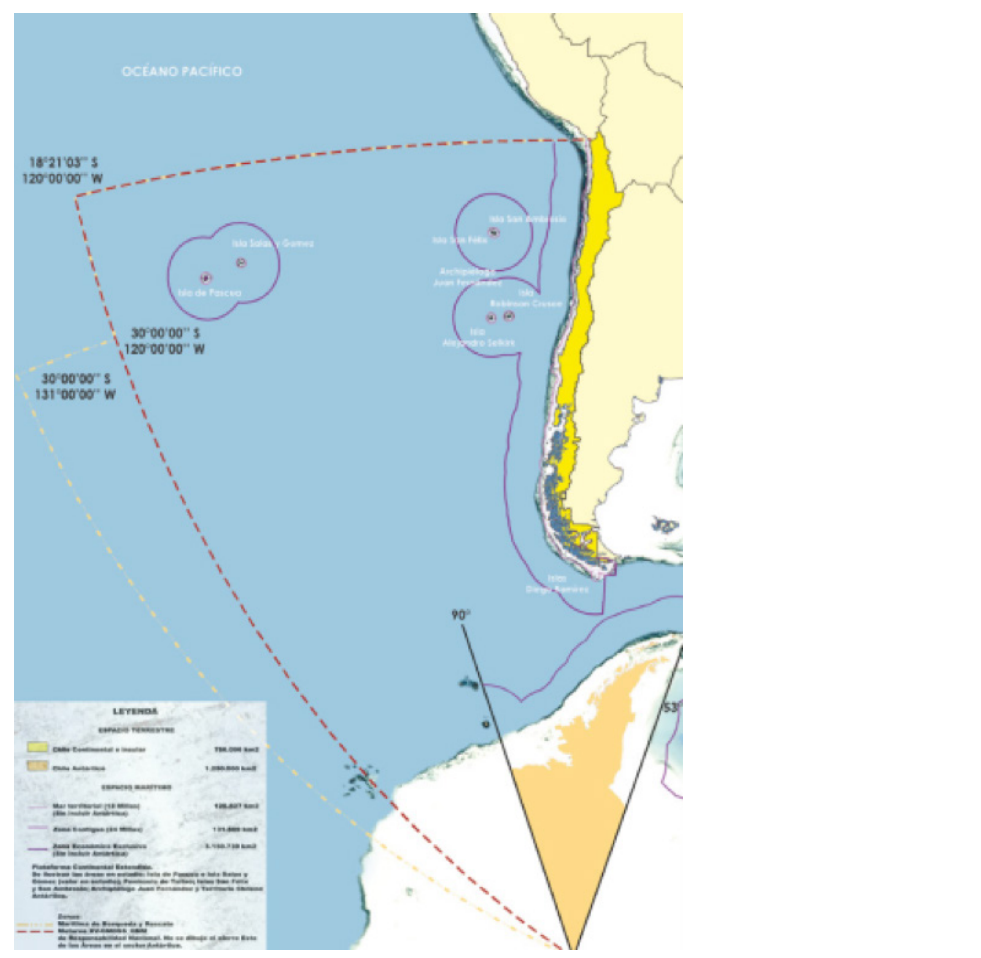

Fuente: Ministerio de Defensa de Chile (2010: 37).

En síntesis, ambos países tienen una vocación marítima innegable para conectarse con el mundo a través de sus puertos. Este es un elemento clave para sus economías, y de ahí la importancia que le dan a las rutas y conexiones marítimas. En el siglo XIX eran las vías de comunicaciones marítimas y el comercio con los mercados europeos, a los que se exportaban productos similares, los que hacían que se compitiese con herramientas similares (Aljovín y Cavieres 2005: 12-13). Desde su nacimiento como Estados independientes, ambos países han tenido una historia de competencia entre sus principales puertos, el Callao y Valparaíso, y han estado en una lucha por obtener la primacía en el Pacífico sur 
para así convertirse en un punto pivote para el comercio en la subregión. Esta es una constante en el panorama de ambos países. Posteriormente a las ideas sostenidas por O’Higgins y Portales a inicios de la República (ver ut supra), este pensamiento en Chile se mantuvo. En efecto, en 1880, durante la Guerra del Pacífico el Canciller chileno José Manuel Balmaceda, en una sesión de la Cámara de Diputados de su país, sostuvo:

Razones históricas legendarias, geográficas e industriales hacían necesario llevar la guerra a su último término. En el litoral del Pacífico de la América del Sur, no hay sino dos centros de acción y progreso: Lima y el Callao, Santiago y Valparaíso; es preciso que uno de estos dos centros sucumba, para que el otro se levante (García 1928: 192).

Y esta visión de competencia en el tema portuario aún se mantiene en el presente siglo. ${ }^{9}$

Esta visión de la importancia estratégica de los puertos y las rutas marítimas también se observa en el Perú que busca, al igual que Chile, ser un centro de conexión regional entre el Asia-Pacífico y el Atlántico, tal como se define en el Libro Blanco de la Defensa del Perú:

El comercio internacional en el siglo XXI demandará de 'megapuertos' para recibir los grandes navíos que servirán de transporte masivo para el comercio mundial. En un mundo globalizado, esta necesidad nos obliga a planificar el desarrollo de una infraestructura portuaria para competir ventajosamente y para participar activamente en la cuenca del Pacífico y para facilitar a los países atlánticos de Sudamérica acceso más directo hacia la cuenca del Pacífico (Ministerio de Defensa del Perú 2005: 49-50).

De acuerdo a estudios de la CEPAL (2015: 7), en el Pacífico sur el principal puerto es el del Callao, seguido por Guayaquil (Ecuador), San Antonio y Valparaíso (Chile, ambos muy cerca el uno del otro). Vemos así que la antigua rivalidad entre el principal puerto peruano y chileno todavía está vigente, aunque esta superioridad cambia a favor de Chile si se toma en cuenta el íntegro de los puertos nacionales de cada país. Las condiciones geográficas hacen que el puerto del Callao sea más accesible que el de Valparaíso para el comercio, en especial con los países de Norteamérica y de la cuenca del Pacífico, su acceso es fácil y el mar tranquilo. Por el contrario, la posición más austral de Valparaíso (1,306 millas marinas más al sur del Callao) así como el hecho que este último de tiempo en tiempo sufre de fuertes oleajes, hacen que el Callao sea un mejor puerto para el comercio (Coca y Compés 2003). Y es con la aparición del polo

\footnotetext{
9 A modo ilustrativo véanse las siguientes noticias donde se destaca la competencia entre el Callao y Valparaíso-San Antonio por mejorar sus condiciones como centros de conexión en la región: «Presidente García estima que puerto del Callao superará dentro de poco al de Valparaíso» (Andina 2009) y «Expansión de Callao amenazaría a los puertos de Valparaíso y San Antonio» (Mundo Marítimo 2011).
} 
Asia-Pacífico, como el gran motor de la economía mundial, y el traspaso del mayor peso económico global de la cuenca del Atlántico a la del Pacífico, que la importancia estratégica de estos dos puertos aumenta.

En la actualidad la principal proyección de ambos países es hacia la cuenca del Asia-Pacífico. Las 21 economías del Foro de Cooperación Económica del Asia-Pacífico (APEC) representan el 40\% de la población del planeta, el 57\% de la producción mundial y el 49\% del comercio internacional (APEC 2016). En APEC están representadas todas las áreas de la cuenca del Pacífico, y el Perú y Chile son las dos únicas economías de América del Sur que pertenecen al APEC, y buscan ser el punto de contacto entre las economías del AsiaPacífico con el subcontinente. Ambos países tienen una visión biocéanica, cuyo objetivo es servir de conexión entre el Pacífico y las costas del Atlántico, con proyección hacia los mercados del Brasil, los más grandes de Sudamérica. A modo ilustrativo, solo la economía de Sao Paulo representa más del 30\% de la economía brasileña (Lancelot et al. 2014), y es cerca de 1.7 veces mayor que el PBI conjunto del Perú y Chile. ${ }^{10}$ Es pues evidente el enorme potencial para los intercambios económicos que se pueden establecer entre el Atlántico, en especial el brasileño, y el Pacífico; y el puerto/país que mejor pueda conectar ambos océanos verá su movimiento largamente acrecentado, con todos los beneficios que esto acarrea, de ahí que podemos apreciar esa centralidad que le dan los ejes de integración del IIRSA a dichos espacios.

\section{Diagrama 2. Ejes de integración del proyecto IIRSA}

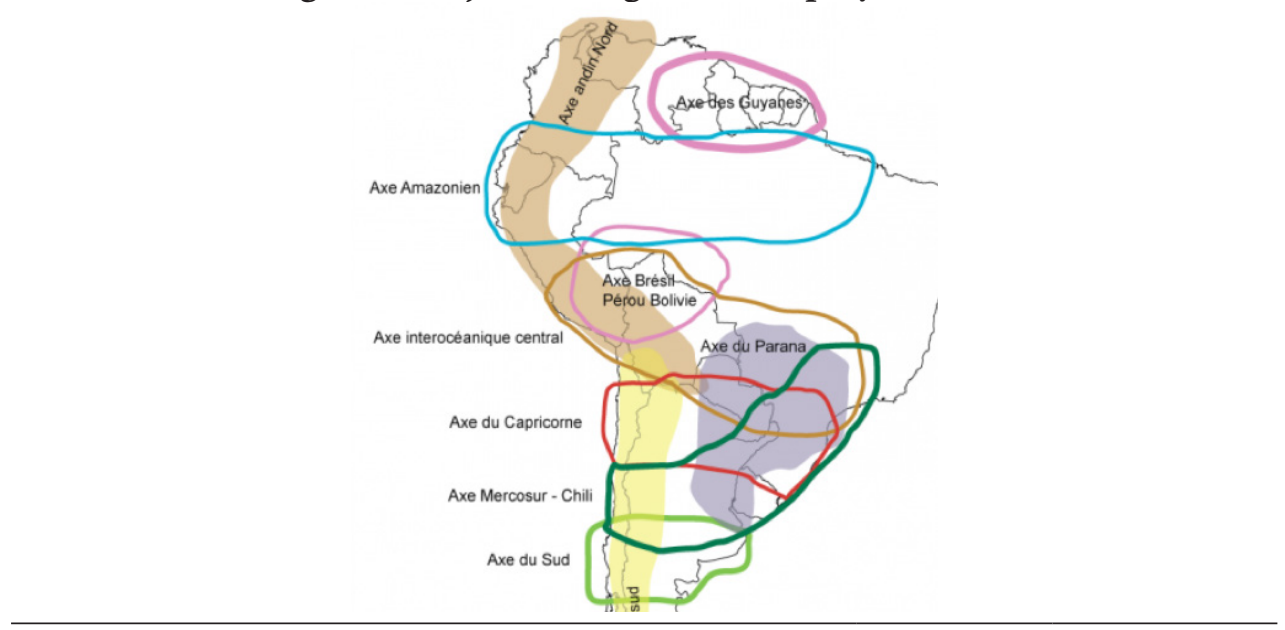

Fuente: Velut (2009).

10 De acuerdo a cifras de la CEPAL. 


\section{EL COMPORTAMIENTO DE LOS ACTORES: ¿DECISIONES RACIONALES?}

Con nuestro estudio de caso hemos puesto a prueba el enfoque constructivista de Wendt, mostrando que la interpretación del realismo que él trata de criticar es la que más se acerca a la relación entre el Perú y Chile a lo largo de la historia.

Ahora, si retomamos el enfoque triangular del interés nacional que plantea Robinson, vemos en la relación momentos de conflicto y rivalidad que corresponden a los intereses de conflicto (competencia por los mercados, disputas por el control de territorios y espacios, o la amenaza estatal por la federación con otro Estado). Pero en otros momentos existen periodos de cooperación, frente a una amenaza externa o para impulsar visiones comunes, en donde primaron los intereses comunes o complementarios (como en la independencia, la guerra contra Espańa de 1866, los acuerdos para proclamar la tesis de soberanía marina sobre 200 millas a fines de 1940, o la Alianza del Pacífico).

Otro elemento que nos llevaría a ver una mayor capacidad explicativa de los paradigmas realistas para entender la posición de las ideas en las relaciones internacionales es el comportamiento histórico de Bolivia. Si, de acuerdo a la hipótesis de Wendt, las relaciones entre los Estados son construcciones sociales entonces sería de esperar que una historia común de alianzas, de conflicto y guerra en contra de un enemigo común, Chile (1836 y 1879), deberían haber creado un sólido sentimiento de cooperación y de confianza con el Perú, y de una total desconfianza con Chile. Pero si vemos el comportamiento de Bolivia notaremos que este último ha actuado sobre la base de sus intereses nacionales. En efecto, el interés de obtener para sí el puerto de Arica se vio en su nacimiento como república y tras la Guerra del Pacífico. En los años 1920, frente a la disputa peruano-chilena por la definición respecto de la soberanía de las provincias de Tacna y Arica, Bolivia pugnó por que al menos Arica le fuese entregada. Luego, en 1975, con la negociación de Charaña, Bolivia se acercó a Chile motivada por la esperanza de obtener un acceso soberano al mar, cuando el interés de La Moneda era otro. Posteriormente, en 2004, cuando Bolivia anunció que tenía grandes reservas de gas, el Perú y Chile compitieron por canalizar las exportaciones de dicho producto, en ese contexto Bolivia proclamó su política de "gas por mar» para así tener una herramienta que permitiese aliviar su condición de país mediterráneo. Finalmente, en 2009 el Presidente Morales esbozó la posibilidad de que la demanda por el límite marítimo entre el Perú y Chile se había planteado «para afectar y retrasar una de las posibles soluciones a nuestro pedido histórico, que es acceso soberano al mar» (HoyBolivia 2009), en momentos en que La Paz se encontraba más 
cerca de Santiago cuando se negociaba la llamada «Agenda de los 13 Puntos». Todo esto nos permite observar claramente que el comportamiento mostrado por Bolivia en esos episodios se fundaba en el interés nacional, permanente y primario, de recuperar su presencia marítima.

De acuerdo a lo visto hasta ahora, la evidencia nos indicaría que la relación bilateral del Perú con Chile fue condicionada en sus inicios por los elementos materiales (control del mar, de las rutas de comercio, de los recursos naturales, entre otros), y estos elementos están todavía presentes. Ahora bien, producto de la competencia iniciada por esos factores objetivos los actores desarrollaron ciertas percepciones, imágenes, negativas que influyeron en la relación pero sin llegar a ser los elementos centrales de la relación. Al menos así lo demuestran las primeras tensiones y las dos guerras, que fueron la consecuencia de la búsqueda del control de espacios geográficos y recursos. Las percepciones negativas de rivalidad en el imaginario popular serían por lo tanto el resultado de las guerras y las tensiones, y no a la inversa. De esta manera, en nuestro caso de estudio, se cumple el postulado de Jervis, quien sostiene que a pesar que las ideas tienen consecuencias sobre el comportamiento de los Estados, no las podemos hacer el centro de nuestra atención (2006: 658). Es más, el estudio efectuado demostraría que la negación del valor explicativo de los postulados realistas por parte de los constructivistas no se funda, necesariamente, sobre argumentos sólidos, sino que por el contrario sus planteamientos pueden ser rebatidos.

En nuestro caso de estudio, las evidencias nos llevan a creer que los elementos objetivos de la relación bilateral son tan importantes que por sí mismos pueden explicar el comportamiento de los actores. En efecto, tomemos el enfoque de las «cuerdas separadas» que se dio en la relación bilateral durante el litigio ante la Corte Internacional de Justicia (CIJ) por la controversia respecto de los límites marítimos. En ese contexto la relación bilateral tenía una doble dimensión: la político-diplomática y la económica. Aquella marcada por el litigio ante la CIJ y la otra con una fuerte impronta interdependiente y de cooperación. En ese contexto, si las relaciones entre los actores estuviesen condicionadas solo por los procesos de interacción, como sostiene el constructivismo, la mayor interdependencia debería haber podido contrarrestar las percepciones negativas y haber llevado a una mayor cooperación, reduciendo a la vez las percepciones negativas creadas en el pasado, esto debido a que en la interacción, como plantea Wendt, los actores comienzan a analizar las probabilidades. Sin embargo, en muchos sectores de las sociedades esto no sucedió. En cambio, la idea de los intereses nacionales nos ayuda a conceptualizar mejor este esquema de las «cuerdas separadas». Así, de acuerdo a las premisas realistas se puede suponer 
la primacía de lo político-diplomático, en donde se maneja el peor escenario posible, no excluyéndose la necesidad de la disuasión, para lo que es necesario acumular capacidades militares, de tal forma que en el análisis el conflicto es una variable que no puede descuidarse aun si esta es poco probable que se dé. En el caso peruano-chileno de los últimos años se han podido apreciar ciertos episodios de tensión, los que habrían sido superados en vista de los intereses comunes o complementarios que existen en la relación, y que los han llevado a construir esquemas de diálogo y cooperación, con mayor dinamismo que años atrás.

De igual manera, si la interacción tuviese la capacidad de por sí sola dar forma a las relaciones entre dos Estados, cómo podría explicarse que las relaciones entre el Perú y el Ecuador sean ahora muy cordiales, a pesar que ambos Estados se han visto envueltos en tres conflictos armados durante la segunda mitad del siglo XX (1941, 1981, 1995), y que las percepciones negativas en el imaginario popular no hayan perdurado como en la relación peruano-chilena, cuya última guerra fue hace cerca de 140 ańos atrás. La respuesta a esta pregunta nos lleva nuevamente a privilegiar el mayor peso que tendrían los elementos objetivos sobre los subjetivos en las relaciones internacionales.

No obstante lo anterior, a pesar de la centralidad de los elementos materiales que guían la relación bilateral, las percepciones mutuas y las ideas están fuertemente presentes en la misma, por lo que su influencia no puede ser pasada por alto. Una tendencia que podemos distinguir en el proceso histórico es que la formación de las imágenes comenzó algunos años después de la independencia, con la Guerra de la Confederación, y cuyo punto más alto fue la Guerra del Pacífico. Después de ese momento los Estados comenzaron a crear una cohesión nacional con referencia al enemigo (McEvoy 2010), lo que probablemente incrementó el nivel de competencia, puesto que el valor relativo de la amenaza era mayor: los elementos materiales y su necesidad de acumular capacidades militares se vio influida por el «revanchismo peruano» o por «la actitud predatoria de Chile».

Vemos entonces que si los elementos materiales que marcaron la relación en un inicio aún están presentes, las emociones también lo están. En ese caso la interacción sí es importante, puesto que las percepciones ayudarían a moldear las relaciones entre actores. Eso es coherente con la opinión de Jervis (2006), quien sostiene que las acciones no producen solamente percepciones, sino que una vez formadas las percepciones influyen al mismo tiempo en las acciones siguientes. 
No obstante la superioridad explicativa de las herramientas realistas sobre las constructivistas que hemos encontrado en este caso, el realismo carece de dar un lugar concreto a las percepciones a pesar que muchos de sus autores sí las reconocen como un elemento presente en la política internacional. Si bien las herramientas realistas tienen la capacidad de explicar el comportamiento de los actores, no pueden dar una explicación a la totalidad de sus elecciones. Ahora bien, es interesante notar la convergencia que hemos podido encontrar entre los textos de algunos autores racionalistas y los epistémicos en lo concerniente a la interacción de los actores. Así, el caso analizado nos indica que las relaciones entre los Estados pueden ser el producto del esquema propuesto por Wendt: existe un momento inicial seguido por un proceso de interacción. Pero contrariamente a la opinión de Wendt, ese momento inicial no estuvo marcado por las ideas y los cálculos de posibilidades, sino que ese momento estuvo definido por los elementos objetivos, las capacidades materiales, los intereses nacionales. El estudio hecho muestra que esos elementos objetivos, intereses, son fijos y están siempre presentes en las relaciones interestatales, por lo que tienen una relevancia de primer orden en la política exterior de un Estado. Sin embargo, el proceso de interacción posterior comienza a crear imagenes, positivas o negativas, las que tienen la capacidad de modificar el valor relativo de aquellos asuntos en juego, ligados a los intereses de cada actor.

\section{Bibliografía}

Aljovín, Cristóbal y Eduardo Cavieres (Comp.) (2005). Chile-Perú; Perú-Chile en el siglo XIX. Valparaíso: Pontificia Universidad Católica de Valparaíso.

Andina (2009). «Presidente García estima que puerto del Callao superará dentro de poco al de Valparaíso». [Online] Andina. Del Perú al mundo. Lima, 23 de agosto.

http://www.andina.com.pe/agencia/noticia-presidente-garcia-estima-puerto-del-callao-superaradentro-poco-al-valparaiso-249863.aspx

APEC (2016). Asia-Pacific Economic Cooperation. [Online] Última consulta: 25 de octubre de 2016. http://www.apec.org/About-Us/About-APEC/Achievements\%20and\%20Benefits.aspx

Armada de Chile (2009). Doctrina Marítima. Valparaíso.

Aron, Raymond (1984). Paix et Guerre entre les Nations. Paris: Calmann-Lévy.

Basadre, Jorge (1983). Historia de la República del Perú, 1822-1933. Vol. III-IV-VI. Lima: Editorial Universitaria.

Basadre, Jorge (1987). «Reconsideraciones sobre el Problema Histórico de la Confederación PerúBoliviana». En Flores Galindo, Alberto (Ed.). Independencia y Revolución. Lima: Instituto Nacional de Cultura. 
Brecher, Michael (1999). «International Studies in the Twentieth Century and Beyond: Flawed Dichotomies, Synthesis, Cumulation: ISA Presidential Address». International Studies Quarterly. Vol. 43, No. 2.

Bull, Benedict, Morten Bøås y Desmond Mcneil (2004). «Private Sector Influence in the Multilateral System: A Changing Structure of World Governance?». Global Governance. Vol. 10:4, octubre/ diciembre.

Centro de Estudios y de la Realidad Contemporánea (octubre, 2006). Informe de prensa, encuesta nacional. Santiago.

Centro de Investigación y Docencia Económicas (2009). Las Américas y el Mundo: Politica exterior y opinión pública en Colombia, Chile, México y Perú 2008. México

Cepal (2015). «Nuevos escenarios del transporte marítimo». Boletín FAL. Santiago, edición No 338, número 2, diciembre.

Chaupadre, Aymerie (2003). Géopolitique. Constantes et changements dans l'histoire. Paris: Ellipses.

Coca, Pedro \& Raúl Compés (Dir.) (2003). Evaluación de los principales puertos de América del Sur. Universidad Politécnica de Valencia-IIRSA.

Fuentes, Claudio y Paz Milet (1997). Chile-Bolivia-Perú: los nuevos desafíos de la integración. Santiago: FLACSO.

García Bedoya, Carlos (1981). Política Exterior Peruana. Lima: Mosca Azul.

García Salazar, Arturo (1928). Resumen de Historia Diplomática del Perú. 1820-1884. Lima: Talleres Gráficos Sanmartí \& cía.

Gestión (2009a). «La inversión de Chile en Perú bate récord en el primer semestre». Diario Gestión. Lima, 29 de noviembre de $/ 2009$.

Gestión (2009b). «Brasil es el mejor amigo del Perú». Diario Gestión. Lima, 16 de noviembre de 2009.

Goldstein, Judith and Robert KEOHANE (1993). Ideas and Foreign Policy: Beliefs, Institutions and Political Change. New York: Cornell University Press.

HoyBolivia (2009). «Se tensionan relaciones entre Bolivia y Perú por declaraciones de Alan García». [Online] HoyBolivia. El primer periódico virtual. La Paz, 26 de marzo de 2009. http://hoybolivia.com/Noticia.php?IdEdicion=8\&IdSeccion=1 \&IdNoticia=12662

Jervis, Robert (1968). «Hypotheses on Misperception». World Politics. Vol. 20, № 3. https:/doi.org/10.2307/2009777

Jervis, Robert (1976). Perception and Misperception in International Politics. New Jersey: Princeton University Press.

Jervis, Robert (1978). «Cooperation under the security dilemma». World Politics. Vol. 30, No 2, pp. $167-21$. https:/doi.org/10.2307/2009958

Jervis, Robert (1988). «Realism, Game Theory, and Cooperation». World Politics. Vol. 40, No 3. https:/doi.org/10.2307/2010216

Jervis, Robert (2006). «Understanding Beliefs». Political Psychology. Vol. 27, № 5. https:/doi.org/10.1111/j.1467-9221.2006.00527.x

Kahhat, Farid. «Las relaciones entre Chile y Perú: entre la cooperación y la desconfianza». Revista Fuerzas Armadas y Sociedad. Año 20, No 1. FLACSO-Chile.

Keohane, Robert y Joseph NYE (2001). Power and Interdependence; World Politics in Transition. 3era edición. Estados Unidos: Longman.

Lancelot, Eric; Miguel Navarro-Martin y Edith Quintrell (2014). Leveraging World Bank Group balance sheet to mobilize financing for a transport project in Brazil. Treasury case study. Washington D.C.: World Bank Group.

Legro, Jeffrey y Andrew Moravcsik (1999). «Is Anybody Still a Realist?». International Security. Vol. 24, No. 2. 
https:/doi.org/10.1162/016228899560130

Leyton, Cristian (2006). «Naturaleza y estructura de rivalidad histórica entre Chile-Perú». Cuaderno de Difusión. Mayo, No 24. Chile: Academia de Guerra del Ejército de Chile.

McEvoy, Carmen (2010). «La guerra que unió a Chile» [entrevista]. En Diario La República. Lima, 21/03/2010.

Mearsheimer, John (1995). «A realist reply». International Security. Vol. 20, № 1. https:/doi.org/10.2307/2539218

Mearsheimer, John (2005). «Better to Be Godzilla than Bambi». Foreign Policy. No 146, enero/febrero.

Milet, Paz (2004). «Chile-Perú, las dos caras de un espejo». Revista de Ciencia Politica. Volumen XXIV, No 2. Pontificia Universidad Católica de Chile. https:/doi.org/10.4067/S0718-090X2004000200015

Ministerio de Defensa de Chile (2002). Libro Blanco de la Defensa de Chile. Santiago.

Ministerio de Defensa de Chile (2010). Libro Blanco de la Defensa de Chile. Santiago.

Ministerio de Defensa del Perú (2005). Libro Blanco de la Defensa del Perú. Lima.

Ministerio de Relaciones Exteriores de Chile (2010). Hitos de la Politica Exterior, 2006-2010. Santiago.

Morgenthau, Hans (1993). Politics Among Nations. Estados Unidos: Brief Edition, Mc Graw Hill.

Mundo Marítimo (2011). «Expansión de Callao amenazaría a los puertos de Valparaíso y San Antonio». [Online] Mundo Marítimo. Información marítima de Latinoamérica. 16 de diciembre. http://www.mundomaritimo.cl/noticias/expansion-de-callao-amenazaria-a-los-puertos-devalparaiso-y-san-antonio

Pinochet, Augusto (1977). Geopolitica. Santiago: Editorial Andres Bello.

Posen, Barry (1993). «The security dilemma an ethnic conflict». Survival. Vol. 35, N 1, pp. 27-47. https:/doi.org/10.1080/03050628808434695

Robinson, Thomas (1969). «National Interests». En Rosenau, James (Ed.). International Politics and Foreign Policy. 2da edición. Nueva York: Free Pr.

Roche, Jean-Jacques (2005). Relations Internationales. Manuel. 3era edición. Paris: Montchrestien.

Singer, J. David (1987). «Reconstructing the Correlates of War Dataset on Material Capabilities of States, 1816-1985" International Interactions, 14: pp. 115-132

Singer, J. David, Stuart Bremer, and John Stuckey (1972). «Capability Distribution, Uncertainty, and Major Power War, 1820-1965». En Russett, Bruce (ed) Peace, War, and Numbers. Beverly Hills: Sage, pp. 19-48.

Sprout, Harold \& Margaret Sprout (1957). «Environmental Factors in the Study of International Politics». The Journal of Conflict Resolution. Vol. 1, No. 4. https:/doi.org/10.1177/002200275700100401

Velut, Sébastien (2009). «Argentine - Chili : Une si longue frontière», Confins. Institut des hautes études d'Amérique latine (IHEAL), (http://confins.revues.org/6095) https:/doi.org/10.4000/confins.6095

Villalobos, Sergio (1990) "Portales: Una falsificación histórica", Santiago: Editorial Universitaria.

Wendt, Alexander (1992). «Anarchy is what States Make of it: The Social Construction of Power Politics». International Organization. Vol. 46, No 2. https:/doi.org/10.1017/S0020818300027764

Wendt, Alexander (1999). Social Theory of International Politics. Cambridge: Cambridge University Press. https:/doi.org/10.1017/CBO9780511612183 